\title{
Reform of the United Nations Security Council: equity and efficiency
}

\author{
Matthew Gould ${ }^{1}$ (D) Matthew D. Rablen ${ }^{2}$
}

Received: 9 November 2016/Accepted: 5 July 2017/Published online: 14 July 2017

(C) The Author(s) 2017. This article is an open access publication

\begin{abstract}
The United Nations Security Council (UNSC) is critical to global peace and security, yet more than 20 years of negotiations over its reform have proved fruitless. We use recent advances in the theory of a priori voting power to present a formal quantitative appraisal of the implications for democratic equity and efficiency of the "structural reforms" contained within 11 current reform proposals, as well as the separate effect of expansion of the UNSC membership. Only one reform proposal-a weakening of the veto power for Permanent Members by requiring two negative votes for a veto to be effectiverobustly dominates the status quo against our measures of equity and efficiency. Several proposed structural reforms may actually worsen the issues they ostensibly claim to resolve.
\end{abstract}

Keywords United Nations · United Nations Security Council · United Nations Security Council reform $\cdot$ Equity $\cdot$ Efficiency $\cdot$ Voting power $\cdot$ Square-root rule

JEL Classification D72 $\cdot$ D71 $\cdot$ C71 · C63

Matthew Gould

gouldma@westminster.ac.uk

Matthew D. Rablen

m.rablen@sheffield.ac.uk

1 Westminster Business School, University of Westminster, 35 Marylebone Road, London NW1 5LS, UK

2 Department of Economics, University of Sheffield, 9 Mappin Street, Sheffield S1 4DT, UK 
"No reform of the UN will be complete without the reform of the Security Council".

- Former Secretary-General of the United Nations Kofi Annan.

\section{Introduction}

The United Nations (UN) is the foremost international body responsible for the maintenance of international peace and security. The UN Security Council (UNSC) is its most powerful organ, with the authority to make legally binding resolutions to fulfil its mandate of maintaining international peace and security. To that end, it can suspend economic and diplomatic relations between countries, impose blockades, and authorize the use of armed force.

Our study appraises possible reforms to the UNSC's collective choice processes. Since its beginnings in 1946, the UNSC has undergone reform only once: in 1963, the UN General Assembly (UNGA) - which includes delegates from all UN member countries-voted to expand the UNSC from 11 to 15 members (UNGA 1963). ${ }^{1}$ Momentum for a second round of reform can be traced to 1993, when an Open-ended Working Group (OEWG) was established to explore proposals for UNSC reform. ${ }^{2}$ This Working Group, now often dubbed the "Neverending Working Group", has entered its 24th consecutive year of deliberations.

This paper presents, to our knowledge, the first formal quantitative study of the equity and efficiency properties of a wide range of proposals that are under consideration by world leaders, having been put forward by a variety of actors within the UN. We apply new formal equity measures developed in Gould and Rablen (2016) to understand the effects of eight "structural reforms" contained within these proposals, as well as the separate effects of expanding the UNSC membership. A key aspect of the implementation is a computer simulation of UNSC membership under each structural reform.

Under the present arrangements, the 15 UNSC members comprise five Permanent Members (PMs) — China, France, Russia, the United Kingdom and the United States - that are ever-present and wield a veto on all non-procedural matters. The remaining ten members are elected Non-Permanent Members (NPMs), who serve time-limited 2-year terms. The ten NPM seats are divided between five regional caucusing groups: one country from Eastern Europe (EE); two countries from each of the Western European and Others Group (WEOG), the Latin America and Caribbean Group (GRULAC-el Grupo Latinoamericano y Caribeño) and Asia; and three countries from Africa. ${ }^{3}$

Two distinct sets of criticisms are widely levelled against these arrangements: one relating to the efficiency with which they allow the UNSC to respond to its member's preferences, and another relating to the degree to which they achieve democratic equity in the allocation of power. ${ }^{4}$

On efficiency grounds, critics argue that the UNSC is too often impotent, not least because a preference against a resolution by a single PM can override a preference for the

\footnotetext{
${ }_{1}^{1}$ The reform did not come into effect until 1965, however.

${ }^{2}$ In full, the Open-ended Working Group on the Question of Equitable Representation and Increase in the Membership of the Security Council (OEWG 1994). The call for the creation of the OEWG in UNGA (1993) followed an overwhelming response to an earlier UNGA Resolution (UNGA 1992), which invited members to submit written comments on a possible review of the UNSC.

${ }^{3}$ See Appendix 3 for the full membership of each of the regional groups (excluding PMs). Of the PMs, China is a member in Asia, Russia in EE, and France and the United Kingdom in the WEOG. Technically, the United States is not a member of any regional group, but it attends meetings of the WEOG as an observer and is considered to be a member of that group for electoral purposes (UN 2012a). For the purposes of this paper, therefore, we give the United States membership in the WEOG.

${ }^{4}$ Perhaps owing to disenfranchisement within the organization, many countries fail to pay their assessed contributions: as of the end of 2011, the UN was owed $\$ 454$ million by member states (UN 2012b).
} 
resolution by all remaining members. For instance, the UNSC is presently under criticism for its inability to respond decisively to the conflict in Syria. The UNSC also has appeared slow to react to earlier conflicts, notably the 1994 genocide in Rwanda (Barnett 2002). This lack of efficiency has sometimes led countries to bypass the UNSC in favor of alternative multilateral action, which is observed in the ongoing Syrian conflict and in previous conflicts. For instance, in 1999 NATO undertook military action in Kosovo, and in 2003 the United States and its allies invaded Iraq, on both occasions lacking a UNSC mandate.

On democratic equity grounds, it is widely acknowledged that the UNSC needs to be seen as fair and legitimate in order to effectively fulfill its mandate (Frey and Stutzer 2006; Stutzer and Frey 2006; Marchetti 2008; Cowling et al. 2010). Critics (e.g., Russett et al. 1996; Hammer 2002; Schwartzberg 2003; Annan 2005; Blum 2005) raise two distinct sets of issues, one relating to equity at the country level, and the other relating to equity at the level of regions. Assessing these claims, the study of Gould and Rablen (2016) finds that, at the level of countries, the conjunction of preferential voting power when a member of the UNSC and the right to be ever-present gives the PMs substantially too much representation. There is thus a need to dilute the representation of the PMs. At the level of regions, the authors also uncover significant levels of inequity-Asia and Africa are both substantially underrepresented, while EE and the WEOG are both heavily overrepresented. This implies a broader representational imbalance between North (EE and the WEOG) and South (Africa, Asia and the GRULAC).

We appraise eight proposed reforms to the UNSC's rules ("structural" reforms) that appear within 11 recent reform proposals. We then analyze separately the impact of expanding the membership of the UNSC above the current 15 members through the addition of new NPM seats. We find disappointing results for the structural reforms considered: only one of the eight improve upon the status quo in both the equity and efficiency dimensions, one leaves efficiency unchanged and improves equity, five leave efficiency unchanged but worsen equity, and one strictly worsens both equity and efficiency. Enlarging the UNSC's membership does permit an improvement in equity, but is no panacea, for it comes at the price of worsened efficiency. Moreover, the equity gains from expansion display diminishing returns, while the costs in terms of lost efficiency display increasing returns.

Of the 11 reform proposals we consider (which typically bundle one or more structural reforms with some degree of membership expansion), we again find that only one is superior to the status quo in both the equity and efficiency dimensions. We show that a simple dominance criterion ranks all but three of the 11 reform proposals (by this criterion the remaining eight reforms may be disregarded).

The most promising structural reform we consider is to require two PMs to vote against a resolution for a veto to be effective. This reform improves both equity and efficiency, but, like any proposal for reform of the UNSC, faces severe political constraints. Overall, we fail to see that any of the reform proposals presently under consideration will (or should) break the reform impasse.

Earlier quantitative studies of UNSC reform include Volacu (2015), Hosli et al. (2011), Strand and Rapkin (2011), O'Neill (1996) and Kerby and Gøberler (1996). In the absence of a formal theoretical framework for measuring equity in such bodies, or for addressing issues relating to region- and country-specific notions of equity, these studies describe the implications of different reforms for the voting power of a PM relative to a NPM, often focusing on the ratio of these quantities. As equity in the UNSC is a function of how often countries gain membership as well as the voting rights they exercise when a member, however, approaches that focus on only one of these dimensions give only a partial view. 
This point is of particular relevance as several of the reforms we shall consider vary only the probabilities of UN membership, leaving voting rights unchanged. In capturing both of these dimensions, the theoretical framework of Gould and Rablen (2016) permits, for the first time, a formal quantitative assessment of the equitability of UNSC reforms for both individual countries and regions, and of how equity interacts with efficiency.

As in Gould and Rablen (2016), we allow for countries to abstain in UNSC voting. In contrast, the studies cited above, and many precursors in the literature (e.g., Shapley and Shubik 1954; Straffin 1983, 1993), model the UNSC's decision rule as permitting members to vote for or against a resolution only. As discussed in Felsenthal and Machover (1997) and Freixas and Zwicker (2003), however, the UNSC's decision rule cannot be faithfully represented in this way. The difficulty is that the UN Charter states that decisions over nonprocedural matters are made by an affirmative vote of nine or more UNSC members, including the concurring votes of the PMs. A "concurring" vote has come to be understood, in practice, as either an affirmative vote or an abstention (see, e.g., Blum 2005, p. 636), so a negative vote by a PM is distinct from an abstention. When ignoring the distinct role of abstention, a PM is calculated to be ten times as powerful as a NPM under the Banzhaf index of voting power, whereas, when properly accounting for abstention, a PM is only around twice as powerful.

Last, in analyzing reform of the UNSC, this paper contributes to a wider literature that uses measures of a priori voting power to appraise reform options for international voting bodies. Examples include Felsenthal and Machover (2001, 2004, 2007) and Leech (2002a), who analyze reform of the Council of the European Union; Manno (1966), Newcombe et al. (1971) and Dixon (1983), who analyze reform of the UNGA; and Leech (2002b), Leech and Leech (2013) and Rapkin and Strand (2006), who analyze reform of the IMF's Executive Board.

The plan of the paper is as follows: Sect. 2 sets out the theoretical framework; Sect. 3 outlines the structural reforms we consider, and their associated reform proposals; Sect. 4 details the simulation analysis; Sect. 5 presents the results; and Sect. 6 concludes.

\section{Equity and efficiency in the UNSC}

The UNSC in its current form (and under the structural reforms we consider) may be represented as a Council Voting Game (CVG), as proposed by Gould and Rablen (2016). In a CVG, an "assembly" assigns (by election or otherwise) a time-varying subset of its members to a "council". For the purposes of this paper the assembly should be interpreted as the United Nations General Assembly (UNGA), the main deliberative body of the UN containing all 193 of its members, and the council should be interpreted as the UNSC. We partition the UNGA into regional groups $R_{j}$, and we denote by $a_{i j}$ the $i$ th country of region $j$. We allow for the (reformed) UNSC to have different membership categories, indexed by $k$. To encompass the various reform proposals, we distinguish membership categories by, for instance, the way in which membership is attained (by Charter-as applies to the category of PM- or by election), the length of term, the provision for immediate reelection and voting rights. 


\subsection{Equity in the UNSC}

We model democratic equity according to the approach developed in Gould and Rablen (2016). We therefore only sketch the approach here, and refer the interested reader to Gould and Rablen (2016) for further details.

\subsubsection{Equity concepts}

Our basic normative notion of democratic equity is that, from behind a veil of ignorance as to what a citizen's preference is, and to which country or region they belong, a citizen should be equally able to influence outcomes in the UNSC. This criterion is referred to in Gould and Rablen as the "equalization of voting power" criterion (for brevity, the EVP criterion). Crucially, we require that the EVP criterion hold before the assignment of countries to the UNSC occurs. That is, we require that expected voting power (before it is known which countries will vote in the UNSC) be equal across citizens. This notion of equity acknowledges that the democratic power of a world citizen in the UNSC depends not only on the voting rights of his or her country when it is a member of the UNSC, but also on how frequently his or her country is a UNSC member.

A strong interpretation of the EVP criterion requires it to hold for each and every resolution. This implies, for instance, that a country with a lower assignment probability in a given year must, by way of compensation, receive more voting power on the UNSC if it is assigned. We, however, employ the so-called weak form of the EVP criterion, which allows for deviations from the EVP criterion in any one year, so long as deviations offset across an infinite sequence of years. Intuitively, the weak form permits inter-temporal shifting of assignment probability and voting rights: a country with, e.g., a lower average assignment probability must be compensated for longer expected spells outside the UNSC by the exercise of greater voting power when a UNSC member.

\subsubsection{The democratic decision-making process}

To measure the proximity of the UNSC under each reform to the EVP criterion we embed the UNSC into a stylized democratic decision-making process that maps the preferences of citizens to UNSC decisions. To analyze differing notions of country-level equity (CE) and region-level equity (RE) we introduce two such decision-making processes: the "country" process (CDP) and the "region" process (RDP). Under the CDP countries on the UNSC are assumed a priori to represent only their national populations, allowing us to investigate equity at the country level. Under the region process (RDP) countries are assumed a priori to act on the UNSC as regional representatives, permitting us to investigate equity at the level of regions.

For a given resolution, the CDP comprises three stages. In Stage 1, a national ballot is held in each country. In Stage 2 a subset of countries is (randomly) assigned to the UNSC from each region. In Stage 3, the UNSC members vote in the UNSC according to the outcomes of their national ballots in Stage 1. In contrast, in the RDP, a single regional ballot is held in each region in Stage 1. In Stage 2 a subset of countries is assigned to the UNSC from each region. In Stage 3, the UNSC members vote as regional blocs on the UNSC, each bloc voting according to the outcome of the regional ballot in Stage $1 .^{5}$

\footnotetext{
5 As, in the context of region equity, we are specifically interested in understanding the representation of regions as cohesive entities it is appropriate in this context to disregard the possibility - which might be very
} 
The rules of the national (regional) ballots in Stage 1 under the CDP (RDP) are as follows. Citizens may vote either \{for, abstain, against $\}$ and the outcome space is \{mandate to vote "for" on the UNSC (mandate for), no mandate, mandate to vote "against" on the UNSC (mandate against) \}. In the event that "no mandate" obtains, the country (or regional bloc under the RDP) is assumed to abstain in the UNSC.

Following Gould and Rablen (2016) we employ a majority threshold rule of the following form: for "mandate for" to obtain, (i) more citizens must vote "for" than vote "against"; and (ii) at least a proportion $\tau \in[0,1]$ of all eligible voters must vote "for". For "mandate against" to obtain, (i) more citizens must vote "against" than vote "for"; and (ii) at least a proportion $\tau$ of all eligible voters must vote "against". In all other eventualities, "no mandate" obtains. We follow Gould and Rablen (2016) in choosing the value of the threshold parameter to be $\tau=1 / 3$.

The stochastic process that assigns UNGA members to the UNSC in Stage 2 is termed the assignment process. For every year $t$, the assignment process induces a probability $p_{i j k t}$ that country $a_{i j}$ is assigned to the UNSC in membership category $k$. The average assignment probability of country $a_{i j}$ on an infinite set of years $t \in T$ is given by $\bar{p}_{i j}=\mathbf{E}_{T, k}\left(p_{i j k}\right)$.

\subsection{Equity concepts-a formalization}

We denote the population of country $a_{i j}$ as $q_{i j} \in \mathbb{N}$, and the population of region $j$ as $q_{j}=\sum_{a_{i j} \in R_{j}} q_{i j}$. Let the absolute voting power of country $a_{i j}$ under the CDP, if assigned to the UNSC, be signified by $\beta_{i j}$. ${ }^{6}$ The absolute voting power of region $j$ under the RDP we denote by $\beta_{j}$. We measure absolute voting power in the Stage 1 vote with the "Banzhaf measure for $(j, k)$ simple voting games" given in Definition 3.4 of Freixas (2005). ${ }^{7}$

Under the assumption - termed uncorrelated preferences (UC) - that every world citizen votes independently, and is equally likely to vote for each of the given voting possibilities, Gould and Rablen (2016) prove that, for CE and RE to obtain, the following conditions must hold ${ }^{8}$ :

$$
\mathrm{CE}: \frac{\bar{p}_{i j} \beta_{i j}}{\sqrt{q_{i j}}} \text { is constant for all } a_{i j} \text {; }
$$

Footnote 5 continued

real in practice - that countries assigned to the UNSC in Stage 2 of the RDP might break ranks and vote according to the preference of their own citizens rather than according to the outcome of the regional ballot. This point underscores the need to understand both country and region concepts of equity.

6 The existing UNSC and the reforms to it we consider may all be analyzed without requiring country voting power to be time-variant.

7 This measure assumes that each voting possibility is chosen with equal probability, which (as we shall subsequently comment on) turns out not to apply to the Stage 3 vote. In Stage 3 we instead we employ the "generalized Bz measure" of Lindner (2008), which allows for the (common) probability of voting "for" or "against" to differ from the probability of voting "abstain". Lindner's measure collapses to that of Freixas when every voting possibility is assigned the same probability.

8 The assumption of UC preferences is not to be understood as denying the possibility of preference correlation, but instead harks to Bernoulli's Principle of Insufficient Reason (BPIR), according to which voting alternatives should be assigned equal epistemic probabilities if there is no known reason for assigning unequal ones (see, e.g., Felsenthal and Machover 1997, 2003). Indeed, were preferences actually uncorrelated within countries and regions, then these constructs would be arbitrary and we would not witness the fierce debates over regional and national representation that we actually observe in the UNSC reform debate. For an analysis of UNSC reform that allows explicitly for preference correlation, see O'Neill (1996). 


$$
\text { RE: } \frac{\beta_{j}}{\sqrt{q_{j}}} \text { is constant for all } R_{j} \text {. }
$$

The condition for CE may be thought of as a probability-augmented version of Penrose's (1946) square-root rule: rather than requiring voting power when a UNSC member, $\beta_{i j}$, to be inversely proportional to $\sqrt{q_{j}}$, it instead requires that expected voting power, $\bar{p}_{i j} \beta_{i j}$, have this property. Unlike for countries, when considering region equity, the assignment probabilities play no role as each region is always represented on the UNSC, and the identities of the countries that form the regional bloc are immaterial.

Under UC preferences, Gould and Rablen compute that countries will vote "for" and "against" in the UNSC with an equal probability, given by $5 / 12 \approx 0.42$. The probability that the Stage 1 vote results in the "no mandate" outcome, leading a country to abstain in the UNSC, is therefore $1 / 6 \approx 0.17$. Thus, as seems realistic, abstention is chosen less often than either of the remaining voting possibilities. Under the RDP, regional blocs vote according to these same probabilities. ${ }^{9}$

\subsection{Measuring deviations from equitability}

We wish to measure, in an objective sense, the proximity of the UNSC (under different reforms) to our two equity concepts. Accordingly, we adopt the metric $d(\mathbf{X}, \mathbf{Y})=1 / 2 \sum\left|X_{i}-Y_{i}\right|$, where $\mathbf{X}$ and $\mathbf{Y}$ are unit-vectors. This corresponds to the widely-used index of distortion, commonly attributed to Loosemore and Hanby (1971). We then define proximity measures on the unit interval (where unity indicates maximal proximity, and zero the minimum possible proximity) for our two equity concepts as

$$
\|C E\|=1-d\left(v^{C E}, \lambda\right) ; \quad\|R E\|=1-d\left(v^{R E}, \lambda\right) ;
$$

where $\boldsymbol{v}^{C E}$ is the scaled $193 \times 1$ unit vector of the $\bar{p}_{i j} \beta_{i j} / \sqrt{q_{i j}}, \boldsymbol{v}^{R E}$ is the scaled $193 \times 1$ unit vector of the $\beta_{j} / \sqrt{q_{j}}$ and $\lambda$ is the $193 \times 1$ unit vector of the constant $1 / 193$.

\subsubsection{A composite measure}

It is helpful for the purposes of comparison between reforms to have a single composite measure of equity. To present our main results we utilize a weighted measure of the form

$$
E=\phi_{C E}\|C E\|+\phi_{R E}\|R E\|,
$$

where $\phi_{i}$ is the preference weight assigned to equity concept $i$, with $\Sigma_{i} \phi_{i}=1$. If the preference weights over country and regional equity of world leaders were known, we clearly would utilize them. As, however, they are not known, we weight these concepts equally to reflect this Bernoullian uncertainty: $\phi_{C E}=\phi_{R E}=1 / 2$. We shall, however, discuss the qualitative changes to our main findings if these weights are made unequal.

\subsection{Efficiency}

Following Felsenthal and Machover (2007, 2009), we take the efficiency of a voting body to refer to the efficiency with which its decision rule responds to the preferences of world

\footnotetext{
9 The actual rate of abstention in the UNSC is given in O'Neill (1996) as being around 2\%. Our qualitative results are robust, however, to rates of abstention below the assumed $17 \%$.
} 
citizens. The more difficult, a priori, it is for a resolution to pass, the lower the efficiency of the decision rule. ${ }^{10}$

Our formal measure of efficiency is based on the "power of a collectivity to act" (PTA) of Coleman (1971), which is the a priori probability of a resolution being approved rather than blocked. Coleman defined his PTA measure only for voting games with two voting alternatives, i.e., \{for, against \}, however. Freixas (2012) generalizes Coleman's measure to allow for abstention, and we further generalize to allow the probability of abstention to be distinct from the common probability of voting "for" or "against". That is, we weigh each winning tripartition by its probability of occurrence, instead of simply counting the number of such tripartitions and dividing by $3^{N} .{ }^{11}$ As our equity measures are scaled to the unit interval, but $P T A$ lies on the interval $(0,1 / 2)$, we report $2 P T A$ as our measure of efficiency. ${ }^{12}$

\section{Proposed UNSC reforms}

Since the 1990s many different proposals for a second reform of the UNSC have been made. ${ }^{13}$ A difficulty, however, with taking these reform proposals themselves as the unit of analysis is that most bundle changes to the UNSC's rules (what we term "structural" reforms) with expansion of the UNSC's membership. ${ }^{14}$ Analysis of reform proposals is, therefore, unable to isolate the effects owing to the structural reform component from those owing to expansion.

A more informative approach—one that allows us to disentangle the effects of the structural reforms separately from the effects of expansion-is to take individual structural reforms as the unit of analysis. Accordingly, we analyze eight structural reforms (Appendix 1) contained within 11 reform proposals put forward by various actors within the UN (Appendix 2). ${ }^{15}$ Note that— to eliminate any effects caused by expansion-each structural

\footnotetext{
${ }^{10}$ Felsenthal and Machover (2007, 2009) consider two further measures of efficiency: the absolute and relative sensitivity indices. As these typically correlate highly with $P T A$, however, we consider this measure only.

11 For a good introduction to PTA, and its relationship to the Banzhaf index, see Leech (2002c).

12 The minimum and maximum possible values of $P T A$ in a proper game when there are $N$ voters are $P T A_{\min }=\operatorname{Pr}(\text { for })^{N} \quad$ and, when $\operatorname{Pr}($ for $)=\operatorname{Pr}$ (against), $P T A_{\max }=1 / 2\left(1-\sum_{i=0}^{\lfloor N / 2\rfloor} \operatorname{Pr}(\text { for })^{i}\right.$ $\left.\operatorname{Pr}(\text { abstain })^{N-2 i} \operatorname{Pr}(\text { against })^{i}(N-2 i, i, i) !\right) . P T A_{\min }$, which converges to zero as $N \rightarrow \infty$, is attained under the unanimity decision rule in which, for a resolution to pass, all members must vote in favor. $P T A_{\max }$, which, if $\operatorname{Pr}($ for $)=\operatorname{Pr}($ against $)$, converges to $1 / 2$ as $N \rightarrow \infty$, is attained under the simple majority decision rule in which the simple majority is taken over all members that do not abstain.

13 See, e.g., Hassler (2013), Cox (2009) and von Freiesleben (2008) for recent qualitative reviews of these reform proposals.

14 The UNSC has not increased in size in line with the growth in UN membership: the ratio of UNSC members to UN members has gone from 0.14 in 1966, to only 0.08 in 2012. Accordingly, there is widespread agreement on the need to expand the membership of the UNSC (although by what degree is hotly disputed).

15 We focus on the structural reforms associated with reform proposals that are sufficiently concrete to be simulated. That rules out some recent, but vague, reform proposals, such as those found in OEWG (2008) and in UfC (2010), and the two NAM reform proposals discussed in Weiss (2005, p. 18). We also omit a number of structural reforms associated with UNSC reform proposals made by academics, notably Model C (Hoffmann and Ariyoruk 2005), Model X (Hoffmann 2006), the REP proposal of Hartwig (2008), and the reform proposals found in Russett, O'Neill and Sutterlin (1996), Schwartzberg (2003) and Strand and Rapkin (2011). We do this as, so far as we know, none of these reform proposals is under detailed consideration by UN members.
} 
reform in Appendix 1 holds the size of the UNSC constant at the present level of 15 members.

The earliest proposal for structural reform we consider is the creation of a new membership category that gives permanent membership of the UNSC, but not the right of veto (Permanent Non-Veto Member-PNVM). The " $2+3$ " reform proposal, which, according to Davis (2010, p. 23), was put forward in 1995 by the Non-Aligned Movement (NAM), was one of the first to embrace the PNVM structural reform. ${ }^{16}$ The creation of a PNVM category is also the only structural reform in the reform proposal, $G 4$, of the "Group of Four" (G4), comprised of Brazil, Germany, India and Japan (G4 2006); and the 1997 reform proposal of Ismail Razali (Razali), then Chair of the OEWG (OEWG 1997).

Nearly all governments wish to abolish or limit the right of veto, which is viewed as an unfair and anachronistic legacy of the Second World War (Fassbender 2004; Schwartzberg 2003). It is widely believed, however, that the five PMs would resist any such change (Weiss and Young 2005). The position of the African Union (AU) is, therefore, that although it opposes the right of veto, if some countries are to have the right of veto, then this right must be extended. Accordingly, the $A U$ reform proposal (AU 2005) has as its structural reform the extension of the right of veto to 11 UNSC members (Veto +$)$. As a fallback position, the AU has joined with several other states (Italy, Mongolia, Singapore and Tunisia), to advocate particular structural reforms aimed at weakening the right of veto. In particular, we analyze the Weak Veto reform proposal $(W V)$, which contains as its structural reform that at least two PMs must vote against a resolution for it to necessarily fail (Veto-). ${ }^{17}$

A further structural reform we consider is the redefining of the existing regional groups (Regional Redefinition-RR). In 2003, the then-UN Secretary-General set up the HighLevel Panel on Threats, Challenges and Change (HLP). The Panel's report (HLP 2004) contains two different reform proposals $-H L P_{A}$ and $H L P_{B}$ - each incorporating a modified set of regions. While $H L P_{A}$ additionally allows for PNVMs, $H L P_{B}$ instead features two new structural reforms. First, it calls for a new category of long-term NPM seats (Term +$)$ with a 4-year term. Second, it proposes that the long-term NPM membership category allow immediate re-election (Renew) - at present, NPMs must wait 1 year before seeking reelection. Allowing renewable membership is also the principal structural reform in the reform proposal of the Uniting for Consensus (UfC) group headed by Italy, denoted UfC (UfC 2005). In 2007, Panama put forward a reform proposal (Panama) that also allows for renewable membership, but with the twist that any member elected to the UNSC for four consecutive terms would acquire PNVM status (Panama 2007).

We consider two further structural reforms, each associated with Italy (which plays an especially active role in the UNSC reform debate). In Italy (2005), it published a reform proposal (Italy) that, as its structural reform, creates a new category of seat that rotates among the members of each regional group (Rotate). A more radical structural reformregional members $(R M)$ - is to create a category of seat held by a region, rather than by any individual country. In this vein, Italy has advocated the creation of a permanent European Union (EU) seat on the UNSC, endowed with the right of veto (the $E U$ reform proposal). ${ }^{18}$ In April 2011, this idea received the backing of the European Parliament, which passed a

\footnotetext{
${ }^{16}$ For more on the origins of this reform proposal, see Fassbender (2004, p. 346) and Bourantonis (2005, p, 49).

17 Fassbender (2004, p. 351) and Wouters and Ruys (2005, p. 22) discuss further the origins of this reform proposal.

18 See, e.g., Kirkup (2009).
} 
Table 1 Structural reforms and associated reform proposals

\begin{tabular}{ll}
\hline Structural reform & Associated reform proposals \\
\hline PNVM seats (PNVM) & $2+3$, G4, HLP, Panama, Razali \\
Renewable seats (Renew) & $H L P_{B}$, Panama, UfC \\
Regional members (RM) & $E U$ \\
Regional rotating seats (Rotate) & Italy \\
Region reallocation (RR) & $H L P_{A}, H L P_{B}$ \\
Increase term length (Term+) & $H L P_{B}$, Panama \\
Expand right of veto (Veto+) & $A U$ \\
Weaken right of veto (Veto-) & WV \\
Do nothing (Present) & Status quo \\
\hline
\end{tabular}

resolution stating that "... a seat in an enlarged UNSC remains a central, long-term goal of the European Union" (European Parliament 2011). ${ }^{19}$

Last, as in any appraisal exercise, we consider the "do nothing" structural reform, named Present. The reform proposal associated with Present we refer to as Status quo.

A summary of the structural reforms and their associated reform proposals is given in Table 1:

\section{Simulation}

To measure proximity to CE requires estimates of the $\bar{p}_{i j}$ under each structural reform. We obtain these estimates through computer simulation of the UNSC assignment process (under each structural reform, and at each degree of expansion) over 100,000 simulated years. In this section, we detail our implementation of this simulation exercise.

We model the UNSC assignment process for all members excluding the PMs (for whom $\bar{p}_{i j}=1$ ) by first giving each country a probability, $\rho_{i j} \in[0,1]$ (where $\sum_{a_{i j} \in R_{j}} \rho_{i j}=1$ ), with which it will be assigned to the UNSC if (i) it competes with all other members of its region; and (ii) only a single seat is being assigned.

We use the empirical estimates of the $\rho_{i j}$ given in Table 1 of Gould and Rablen (2016). These are computed from the empirical analysis of election to the UNSC of Dreher et al. (2014), which shows that three country characteristics systematically predict UNSC election: population, gross national income per capita and waiting time since last serving on the UNSC. The precise details of the simulation model that the empirical estimates of the $\rho_{i j}$ are fed into to yield estimates of the $\bar{p}_{i j}$ will not be of interest to all readers, so these are relegated to Appendix 3.

\subsection{Structural reforms and expansion}

We would like to identify the effects of each structural reform, $s$, in isolation of the effects of expansion. We therefore create the $\mathrm{CVG} C_{S}$ associated with each structural reform $s$. For example, $C_{P N V M}$, is created from $C_{P r e s e n t}$ by reducing by one the number of NPM seats for Africa, Asia, GRULAC and the WEOG in the present UNSC, and adding one new PNVM

19 The EU already enjoys observer status in the UNGA under Resolution A/65/L.64/Rev.1 (UNGA 2011). As an observer, the EU has the right to speak at UNGA meetings and to present proposals agreed by EU members, but not the right to vote on resolutions and other substantive matters. 
seat for each of these regions. To then observe separately the effects of expansion, we increase the size of the UNSC under each structural reform by adding new NPM seats oneby-one until $N=30 .{ }^{20} \mathrm{We}$ are obliged to specify how each additional seat is assigned to a region. As the response of our measures varies greatly depending upon this factor, if additional seats are assigned to regions according to a deterministic pattern, this introduces a cyclical form of noise into our results that obscures almost entirely the underlying trend. To uncover the trend, therefore, we assign each new seat to a region in a probabilistic manner (in a manner we explain precisely in Appendix 3). Accordingly, we split the 100,000 simulated elections performed across different partitions of seats to regions. Our reported results are the average values given by this process. $^{21}$

\subsection{Voting power and decision rule}

At present, the UNSC decision rule requires, as a necessary condition, that nine of 15 members, i.e., $60 \%$, vote in favor of a resolution for it to pass. Although it is conceivable that this $60 \%$ threshold might be altered as part of a reform of the UNSC, the benchmark analysis is performed here under the assumption that the $60 \%$ threshold remains unchanged. We shall, however, comment on the implications of allowing this threshold to change.

As the UNSC is expanded beyond 15 seats, however, it is only possible to retain exactly the ratio $9 / 15=0.6$ when $N$, the number of UNSC members, is divisible by five. One option, when $N$ is not divisible by five, is to set the threshold number of members required for a decision to pass, $Q_{N}$, such that the fraction $Q_{N} / N$ is made as close as possible to 0.6. This, however, again introduces noise into the results that obscures the underlying trend. Instead we adopt a probabilistic approach that sets the threshold to the closest integer values either side of $0.6 \mathrm{~N}$ in such a way that the mean value of the threshold is $0.6 N$. Specifically, if $0.6 N$ is an integer then $Q_{N}=0.6 N$; otherwise $Q_{N}=\lfloor 0.6 N\rfloor$ with probability $\lceil 0.6 N\rceil-0.6 N$, and $Q_{N}=\lfloor 0.6 N\rfloor$ with probability $\lceil 0.6 N\rceil-0.6 N$. Again, our reported results are averages over 100,000 iterations of this probabilistic process at each degree of expansion. With the threshold thus specified, we compute the absolute voting power of each category of UNSC membership using the method of generating functions (see, e.g., Freixas 2012).

\section{Results}

Our main results are shown in Fig. 1. On the horizontal axis is our composite equity measure $E$, and on the vertical axis is our efficiency measure $2 P T A$. As, however, $2 P T A$ becomes very close to zero as the UNSC is expanded, we show the logarithm of $2 P T A$ for visual clarity.

The left-most point of each line in Fig. 1 records the equity and efficiency of the unexpanded (15-member) UNSC under each structural reform. As we then incrementally expand the membership of the UNSC, one member at a time, we form the locus of points

\footnotetext{
${ }^{20}$ We do not analyze cases for which $N>30$ as there is broad agreement among UN members that, in order to be able to perform its role effectively, the UNSC must have a limited number of members (e.g., Zifcak 2006). The largest UNSC expansion advocated in the reform proposals we consider is 11 new members $(A U)$, which would bring total membership to $N=26$ countries.

21 Precisely, we realize marginally more than 100,000 periods, but discard the very earliest periods. This is necessary as we begin with a UNSC containing just the PMs (with the remaining seats vacant). Hence, it requires a number of years before the elected UNSC becomes filled with members. The number of initial years we discard corresponds to twice the maximum term length.
} 

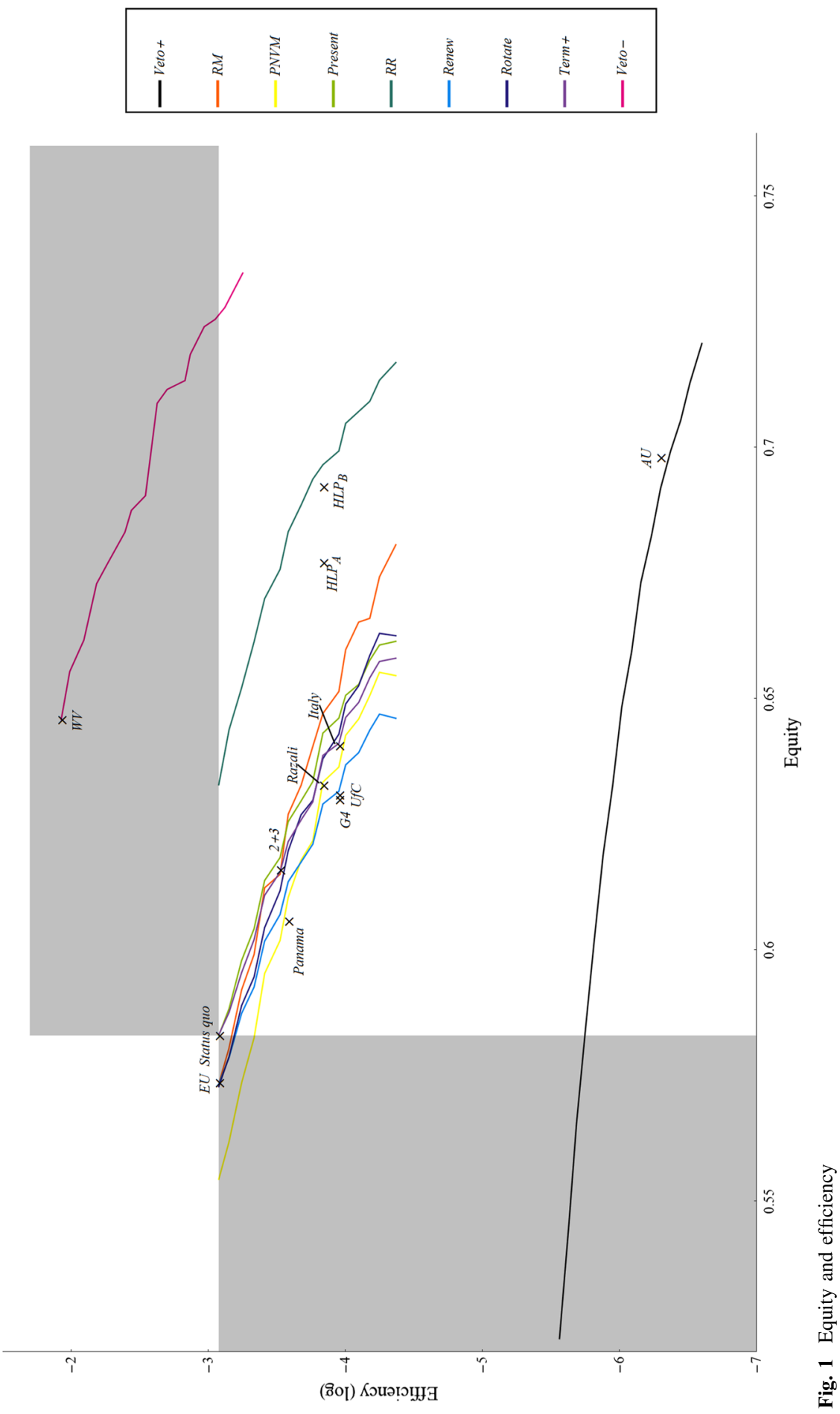
given by each line in Fig. 1. Thus, the right-most point of each line corresponds to the maximally expanded UNSC with 15 additional members (30 members in total). Comparison of the left-most points of each expansion line therefore reveals the pure effect of each structural reform separately from the effects of expansion. Comparison of the lines away from the left-most point reveals the separate effect of expansion of the UNSC under each structural reform.

The equity and efficiency measures for each UNSC reform proposal appear in Fig. 1 as a point estimate, marked " $x$ ". ${ }^{22}$ To help interpret the findings in Fig. 1 we show separately, in Fig. 2, the two components of our summary equity measure (CE and RE) under each structural reform.

\subsection{Structural reforms}

We begin with an appraisal of each structural reform (with no membership expansion). We say that structural reform $i$ "dominates" $j$ if it holds that $P T A_{i}>P T A_{j}$ and $E_{i}>E_{j}$, and that structural reform $i$ "weakly dominates" $j$ if one or both of these inequalities is weak. In Fig. 1, we shade the space that is dominated by Present (to the "south-west"), and the space that dominates Present (to the "north-east").

We see in Fig. 1 that one structural reform, Veto + (under which six existing NPM seats are replaced by six PM seats), is strictly dominated by Present. The effect of Veto+ upon efficiency is deleterious: it reduces the a priori probability of a resolution being approved from $1 \%$ at present to just $0.2 \%$. Veto + also leads to a decline in overall equity: Fig. 2 shows that RE is improved, but $\mathrm{CE}$ is worsened. The improvement in RE arises as Veto + gives four of its six new vetoes to countries from the underrepresented regions of Africa and Asia. The worsening against $\mathrm{CE}$, which turns out to be the dominant effect, arises as Veto + concentrates (rather than dilutes) expected voting power in the hands of the (expanded) set of PMs.

A further five structural reforms are weakly dominated by Present: these are PNVM, Renew, RM, Rotate and Term+. Each of these five structural reforms affect only the probabilities of assignment to the UNSC, leaving voting rights unchanged. It follows that each of these structural reforms leave the efficiency of the UNSC unchanged. With the exception of $R M$, which modifies the existing regional structure by making the EU a single actor, the remaining four structural reforms also leave regional equity unchanged, thereby only altering country equity.

The worst of these five structural reforms (i.e., the one weakly dominated by the remaining four) is seen to be $P N V M$, under which four NPM seats are converted into PNVM seats. The reform is associated with a marked worsening of CE as it concentrates (when it would ideally dilute) the distribution of expected voting power across countries.

The second-worst of the five structural reforms that are weakly dominated by Present is Rotate, under which NPM seats are replaced with seats that rotate within regions. Rotate worsens $\mathrm{CE}$ as it as does not shift expected voting power away from the PMs to the remainder of the UN membership (as would be desirable), but instead reallocates (equalizes) expected voting power within those remaining members. This equalization of

\footnotetext{
${ }^{22}$ Note that, in Fig. 1, not all reform proposals lie on a line associated with a structural reform. There are two reasons for this. Most straightforwardly, some reform proposals combine more than one structural reform, and therefore appear somewhere between the relevant lines. A second reason is that some reform proposals yield expansion proportions (in terms of the proportion of new NPM seats that are allocated to each region) that are different from the "optimal" proportions we employ in the simulation (see Appendix 3).
} 

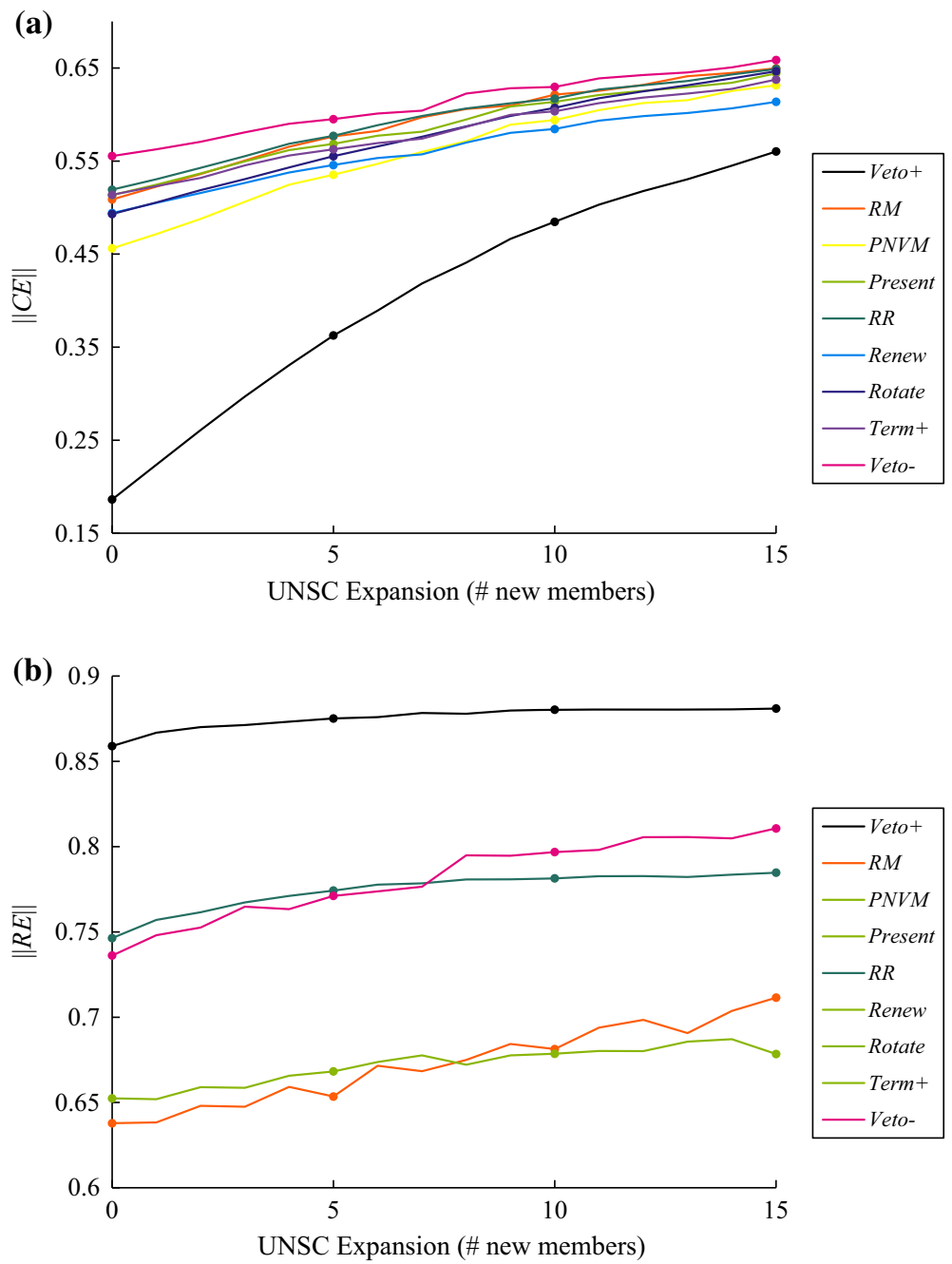

Fig. 2 a Proximity to $\mathrm{CE}$ at each expansion. b Proximity to RE at each expansion

expected voting power is counterproductive, however, for under CE more populous countries warrant greater expected voting power than less populous countries.

The next worst structural reform weakly dominated by Present-Renew-allows reelection as a NPM. Again, Renew alters only proximity to the CE concept. The worsening against this concept arises as permitting reelection benefits disproportionately those countries that gain election more often, but Gould and Rablen (2016) show that such countries already receive at least their equitable level of expected voting power. Accordingly, those countries with higher assignment probabilities become overrepresented, thereby exacerbating the underrepresentation of the remaining countries. 
Next in the chain of weak dominance is $R M$, under which EU members would vote as a single PM. Our modelling of this structural reform utilizes the anticipated membership of the EU as of April 2019 onwards, by which time the United Kingdom will no longer be an EU member state. ${ }^{23}$ According to Fig. 2, the principal effect of this proposal is to worsen regional equity. This arises as the membership of the EE group is reduced when the EU members are removed, causing the remaining members to become highly overrepresented. This effect could be mitigated, however, if implementation of $R M$ were bundled with an appropriate rebalancing of the allocation of seats to regions.

The final structural reform in this group of five is Term +, under which some NPM seats would have extended 8-year terms. As may be seen in Figs. 1 and 2, although the structural reform worsens CE, the effect is only marginal: to a good first approximation Term + has simply no effect at all. ${ }^{24}$

One structural reform does succeed in weakly dominating Present: $R R$. Under $R R$, the five existing regional groupings would reduce to four. This structural reform leaves voting rights, and therefore efficiency, unchanged, but leads to substantial improvements in equity. The bulk of the equity effect is seen in Fig. 2 to be at the region level, for $R R$ disperses some of the excess representation of the WEOG by moving the United States and Canada into the Americas group, and countries such as Australia and New Zealand into the Asia and Pacific group.

Only one structural reform dominates Present: Veto-. Under Veto-, two PMs would need to vote against a resolution for this to constitute an automatic veto. By reducing the blocking power of each PM, Veto- increases the a priori probability of a resolution being approved to $2.21 \%$. The improvement in equity is attributable to discernible improvements in both $\mathrm{CE}$ and RE. The former effect arises as Veto- succeeds in diluting the share of expected voting power held by the PMs (through reducing their voting power); the latter arises as the overrepresentation of EE and the WEOG is eased.

In summary, Veto- aside, the types of structural reform under consideration yield modest, and often negative, effects on equity and efficiency.

\subsection{Expansion}

We now consider the effects of expanding the UNSC's membership under each structural reform. We say that structural reform $i$ "expansion-dominates" $j$ if it holds that $P T A_{i}>P T A_{j}$ and $E_{i}>E_{j}$ for all expansions $x=0,1, \ldots, 15$.

The effects of UNSC expansion are seen in Fig. 1 to be qualitatively similar under each of the different structural reforms: expansion improves equity, but worsens efficiency. Figure 1 indicates that equity is increasing, but at a decreasing rate, in the size of the UNSC. There are, thus, diminishing equity returns to expansion. Efficiency, however, is decreasing, and at an increasing rate, in the size of the UNSC. Thus, incremental expansions of the UNSC generate increasingly large efficiency losses, and increasingly small equity gains. In spite of these qualitative similarities, however, we do see some important quantitative differences in the way expansion interacts with each structural reform, as we shall discuss below.

\footnotetext{
${ }^{23}$ Prior to the United Kingdom expressing in 2016 its intention to leave the EU, RM stood to deliver significant improvements to efficiency, for then the UK and France would have shared the EU veto, rather than both wielding separate vetoes, thereby reducing the number of veto actors from five at present to four.

24 The slight worsening against CE is because longer NPM terms favor countries with higher assignment probabilities at the expense of countries with lower assignment probabilities (which are already underrepresented). To see this, suppose a country is always elected as a NPM when it is eligible. Under the present rules (2-year term), such a country would serve on the UNSC for two in every 3 years (67\%). Were the term increased to four years, such a country would serve on the UNSC for four in every five years $(80 \%)$.
} 
One structural reform expansion-dominates all others: Veto-. In this sense, this structural reform wins out among those we consider. Alongside Veto-, one other structural reform, $R R$, weakly dominates Present at each expansion.

Of the five structural reforms that are weakly dominated by Present in the unexpanded UNSC, three (PNVM, Renew and Term+) are so dominated at every expansion. Note in Fig. 1, however, that the expansion lines for the Rotate and $R M$ structural reforms cross that for Present, indicating that these two structural reforms bring stronger equity benefits from expansion. In particular, if expansion is by six or more new members, $R M$ - under which the EU votes as a single actor-achieves greater equity than does Present.

The other remarkable feature of the expansion lines in Fig. 1 regards Veto +, which goes from being the least equitable structural reform in the unexpanded UNSC to being the second most equitable structural reform in the maximally expanded 30-member UNSC. This arises as each increase in the number of NPMs incrementally lowers the voting power of a PM, thereby improving proximity to CE. Veto + benefits especially from this effect owing to the large number of PMs (i.e., 11) it advocates.

\subsection{Reform proposals}

Last, we consider our results for the reform proposals. Recall that (i) these proposals typically combine expansion of the UNSC with one or more structural reforms (as specified in Appendix 2); and (ii) that each is represented by a " $x$ " in Fig. 1. We say that a reform proposal $i$ "dominates" $j$ if $P T A_{i}>P T A_{j}$ and $E_{i}>E_{j}$.

Only one reform proposal dominates Status quo: $W V$. Under $W V$ two PMs must vote against a resolution for this to constitute a veto. Figure 1 shows that it is possible to augment $W V$ with a significant expansion of the UNSC's membership (by as many as 13 members) while remaining in the region that dominates Status quo (shaded grey in Fig. 1).

Of the remaining reform proposals, bar $E U$, each improves upon equity relative to Status quo, but - because of the added difficulty of achieving the required level of consensus within an expanded body — worsens efficiency. Helpfully—given the proliferation of reform proposals - it transpires that all but three of the reform proposals we consider can be demonstrated to be dominated (and should, therefore, never be chosen). From Fig. 1 we see that Panama is dominated by $2+3$, which is itself dominated by $W V$. Razali and Italy both dominate $G 4$ and $U f C$, but are themselves dominated by $W V . H L P_{A}$ is weakly dominated by $H L P_{B}$, and $E U$ is dominated by Status $q u o$. The three undominated reform proposals are therefore found to be $W V$ (as discussed above), High-Level Plan B $\left(H L P_{B}\right)$, and the reform proposal of the African Union $(A U)$. From Fig. 1 we see that, of the three undominated proposals, $W V$ is the most efficient, while the $A U$ proposal is the most equitable. The $H L P_{B}$ proposal, under which the existing regional groupings would be redrawn and eight new renewable seats with 4-year terms created, emerges as a "middle" candidate, lying between the $W V$ and $A U$ proposals on both the equity and efficiency dimensions.

\subsection{Extensions}

We now briefly consider how our results change if (i) world leaders are willing to reduce $Q_{N} / N$ - the proportion of the total votes required to be affirmative for a resolution to pass - as part of a reform of the UNSC; or (ii) we vary the preference weights in the construction of our composite measure of equity.

Beginning with the level of $Q_{N} / N$, were world leaders willing to lower this value below the current level of 0.6 , this would make it easier for resolutions to pass, and therefore raise efficiency. As such, every expansion line and point estimate in Fig. 1 would shift upwards 
were we to assume a lower value of $Q_{N} / N$, but the relative comparisons between structural reforms would be unaffected. We note, however, that there appears to be little appetite among world leaders to reduce $Q_{N} / N$.

The effects of altering the preference weights in the construction of our composite measure of equity may be inferred from Fig. 2. According to panel (a), Veto- and $R R$, and the associated $W V, H L P_{A}$, and $H L P_{B}$ reform proposals, would be the chief beneficiaries from placing greater weight on country equity. The principal losers would be Veto+, and the associated $A U$ reform proposal. Conversely, Veto + and the associated $A U$ reform proposal would be the principal beneficiaries if more weight were placed on regional equity, while $R M$ and the associated $E U$ reform proposal, would be the principal losers.

\section{Conclusion}

The United Nations Security Council (UNSC) plays an important role in ensuring global peace-the bedrock of macroeconomic stability. Although reform of the UNSC is one of the most pressing issues facing the international community, as yet no previous analysis has appraised the options for UNSC reform against formal equity and efficiency desiderata.

In this paper, we attempted such an appraisal. Given that our analysis rests on a highly simplified theoretical framework that makes use of strong "veil of ignorance" arguments, and which adopts one particular notion of voting power (i.e., Banzhaf's index, instead of, e.g., the index of Shapley and Shubik 1954 employed in O'Neill 1996 and elsewhere), it is appropriate to stress caution in the interpretation of our findings. This caveat notwithstanding, our approach does yield a rich set of predictions for the effects of a wide range of UNSC reform proposals.

Although nearly all countries support expansion of the UNSC's membership, thus far no expansion has taken place, as some countries worry that an expansion-only reform would be merely a "sticking plaster" that ultimately delayed the implementation of deeper "structural" reforms. On the basis of our analysis, we concur that expansion at the levels currently under consideration will provide only modest improvements in equity, and will also come at the expense of efficiency, unless world leaders are also willing to lower the threshold for the proportion of members that must vote in favor of a resolution for it to pass. By segregating the effects of structural reform from those owing to expansion, we also find that, in many cases, the types of deeper structural reforms being proposed are in fact counterproductive in respect of our metrics. As such, in these cases, a reform purely of membership expansion would actually be preferable to expansion alongside structural reform.

The most promising reform proposal among those we consider is one in which two Permanent Members (PMs) would have to cast votes against a resolution to block it $(W V)$. Its success owes to the fact that, by reducing the voting power of the PMs, it dilutes the distribution of expected voting power away from these countries. Regrettably, however, this reform proposal appears stymied in the short- and even medium-term, for no PM is willing to relinquish its right of veto, and the constitutional ability of the PMs to retain these powers seems impregnable. ${ }^{25}$ Accordingly, those hoping for a major change in the efficiency and equity of the UNSC in the short-run are likely to be disappointed. On the other hand, despite their constitutional power, Fassbender (2004) argues that, if the rest of the world could agree on a common way forward, the PMs would have little choice but to concede ground.

25 The San Francisco Declaration of 1945 ensures that a PM can veto questions of veto rights, for a PM exercises a veto on all non-procedural matters and also on whether a matter is to be deemed procedural or non-procedural (see, e.g., Köchler 1995). 
We note that the Weak Veto reform proposal is by no means the only way of weakening the veto right: other, potentially more acceptable, options that weaken the veto to a lesser extent might profitably be explored by world leaders. On this point, Freixas (2005, p. 52) shows that the present UNSC voting rule has a mathematical representation as a "weighted $(3,2)$ voting game" in the sense of Freixas and Zwicker (2003), given by

$$
[9 ; \underbrace{(1,0,-6), \ldots,(1,0,-6)}_{5}, \underbrace{(1,0,0), \ldots,(1,0,0)}_{10}] \text {, }
$$

where nine is the threshold that must be achieved for a vote to pass, and the first, second and third components of each vector denote the weights attached, respectively, to a vote "for", "abstain", and "against". Viewed in this way, a minimal reduction in veto rights can be achieved by lowering the threshold from nine to eight, such that the negative vote of a PM could be overturned only if all other UNSC members were to vote in favor.

The preceding point notwithstanding, it has not been our purpose to offer our own reform proposal, merely to examine those put forward by actors within the UN itself. Going forward, one might look for the "first-best" reform proposal that is "optimal" in respect of our notions of equity and efficiency, or the optimal "second-best" reform that is as proximate as possible to these concepts, when constrained to satisfy a "functionality" or "realpolitik" condition. While these avenues must await a proper treatment, we believe that the present contribution at least clarifies what (little) is achieved by the reform proposals presently on the table.

Acknowledgements We thank an anonymous referee, Vera Eichenauer, Randall Stone, Anton Strezhnev, the participants of PEIO (Bern), the European Public Choice Society Annual Conference (Groningen), and the participants of the Voting Power Analysis with Reference to Institutions of Global Governance workshop (Warwick), for helpful comments on earlier versions of the paper. Gould thanks the University of Westminster for financial support.

Open Access This article is distributed under the terms of the Creative Commons Attribution 4.0 International License (http://creativecommons.org/licenses/by/4.0/), which permits unrestricted use, distribution, and reproduction in any medium, provided you give appropriate credit to the original author(s) and the source, provide a link to the Creative Commons license, and indicate if changes were made.

\section{Appendix 1}

See Table 2.

Table 2 Structural reforms

\begin{tabular}{|c|c|}
\hline Reform & Details \\
\hline$P N V M$ & $\begin{array}{l}\text { Four new PNVM seats (replacing one NPM seat for each of Africa, Asia, the GRULAC and the } \\
\text { WEOG) }{ }^{\mathrm{a}}\end{array}$ \\
\hline Present & Implement no structural reform \\
\hline Renew & All NPM seats made renewable \\
\hline$R M$ & All EU members act jointly as a single PM with the right of veto within the $\mathrm{WEOG}^{\mathrm{b}}$ \\
\hline Rotate & Ten seats that rotate among the region members (replacing existing NPM seats) \\
\hline$R R$ & $\begin{array}{l}\text { New regional groupings: Africa, Asia and Pacific, Europe, and the Americas (three NPMs for } \\
\text { Africa; } 2.5 \text { for each of the Asia and Pacific and the Americas; two for Europe) })^{\mathrm{c}}\end{array}$ \\
\hline Term+ & $\begin{array}{l}\text { Eight seats with a 4-year term (replacing two NPM seats for each of Africa, Asia and the } \\
\text { GRULAC; one NPM seat for each of EE and the WEOG) }\end{array}$ \\
\hline
\end{tabular}


Table 2 continued

\begin{tabular}{ll}
\hline Reform & Details \\
\hline $\begin{array}{l}\text { Veto+ } \\
\text { Six new PM seats with the right of veto (replacing two NPM seats for each of Africa and Asia; } \\
\text { one NPM seat for each of the GRULAC and the WEOG) }\end{array}$ \\
Veto-
\end{tabular}$\quad$\begin{tabular}{l} 
Two PM votes against a resolution required to form a veto \\
\hline
\end{tabular}

${ }^{a}$ We assume that the PNVM seats are given to Nigeria in Africa, India in Asia, Brazil in the GRULAC, and Germany in the WEOG

b As the prospect of reform to the UNSC before April 2019 seems remote, we take the EU membership to be the current $28 \mathrm{EU}$ members less the UK, which will have ceased to be an EU member state by this date

c These proportions are chosen to maintain, insofar as possible, the regional allocation of NPM seats between the existing five regional groups. The two NPM seats currently allocated to the WEOG are split one to Europe, and the other shared (rotated) between the Americas and Asia and Pacific (hence the fractional number of NPMs for these two regions). The new regional groupings are based on the report of the UN's High-level Panel on Threats, Challenges and Change (HLP 2004). The report does not detail the precise membership of each group, but does indicate the number of countries belonging in each (allowing some inference to be made over the intended membership). We assume the Africa group to correspond to the existing Africa group; the Europe group to correspond to the existing EE group and the European countries in the WEOG; Asia and the Pacific to correspond to the existing Asia group with the addition of New Zealand and Australia; and the Americas group to correspond to the existing GRULAC plus Canada and the United States

d As this structural reform is associated with the $A U$ reform proposal we follow Appendix 2 (note 2) in assuming that the new PM seats are given to Nigeria and Egypt in Africa, India and Japan in Asia, Brazil in the GRULAC and Germany in the WEOG

\section{Appendix 2}

See Table 3.

Table 3 Reform proposals

\begin{tabular}{|c|c|}
\hline Proposal & Details \\
\hline $2+3$ & Two new PNVM seats and three new NPM seats (one each for Africa, Asia and the GRULAC) ${ }^{\mathrm{a}}$ \\
\hline$A U$ & $\begin{array}{l}\text { Six new PM seats with the right of veto (two each for Africa and Asia; one each for the } \\
\text { GRULAC and the WEOG) and five new NPM seats (two for Africa; one each for Asia, EE and } \\
\text { the GRULAC) }\end{array}$ \\
\hline$E U$ & All EU members vote jointly as a single PM with the right of veto \\
\hline G4 & $\begin{array}{l}\text { Six new PNVM seats (two each for Africa and Asia; one each for the GRULAC and the WEOG) } \\
\text { and four NPM seats (one each for Africa, Asia, EE and the GRULAC) }\end{array}$ \\
\hline$H L P_{A}$ & $\begin{array}{l}\text { New regional groupings: Africa, Asia and Pacific, Europe, and the Americas. Six new PNVM } \\
\text { seats (two each for Africa and Asia and Pacific; one each for Europe and the Americas). A } \\
\text { total of } 13 \text { NPM seats (four for Africa and Americas; three for Asia and Pacific; two for } \\
\text { Europe) }{ }^{\mathrm{d}}\end{array}$ \\
\hline$H L P_{B}$ & $\begin{array}{l}\text { New regional groupings: Africa, Asia and Pacific, Europe, and the Americas. Eight new } \\
\text { renewable seats with 4-year terms (two for each region). A total of } 11 \mathrm{NPM} \text { seats (four for } \\
\text { Africa; three each for Asia and Pacific and the Americas; one for Europe) }\end{array}$ \\
\hline Italy & $\begin{array}{l}\text { Ten new regional rotating seats (three each for Africa and Asia; two for the GRULAC; one each } \\
\text { for EE and the WEOG) }\end{array}$ \\
\hline Panama & $\begin{array}{l}\text { Six new renewable seats with 5-year terms (two each for Africa and Asia; one each for the } \\
\text { GRULAC and the WEOG) Any country elected for four consecutive terms to these new seats } \\
\text { to become a PNVM }\end{array}$ \\
\hline
\end{tabular}


Table 3 continued

\begin{tabular}{ll}
\hline $\begin{array}{l}\text { Proposal } \\
\text { Status } \\
\text { quo }\end{array}$ & Details \\
Razali & $\begin{array}{c}\text { Do nothing } \\
\text { new NPM seats (one each for Africa, Asia, EE, the GRULAC) }\end{array}$ \\
& $\begin{array}{c}\text { All NPM seats to be renewable. Ten new renewable NPM seats (three each to Africa and Asia; } \\
\text { two for the GRULAC; one each for EE and the WEOG) }\end{array}$ \\
& Two PM votes against a resolution required to form a veto
\end{tabular}

a According to Davis (2010), Germany and Japan were widely seen as deserving the two NPVM seats. We therefore allocate these seats on this basis

b As the identities of the new PMs is not specified, we assume that the new PM seats are allocated to Nigeria and Egypt in Africa, India and Japan in Asia, Brazil in the GRULAC and Germany in the WEOG

c We assume the six new PNVMs to be the same six countries assumed to be PMs in the $A U$ reform proposal

d We assume that the six new PNVMs are identical those in the G4 reform proposal

e Italy (2005) terms the ten new seats as "Regional" seats. Rotation is not proposed explicitly, but, according to Martini (2009: 7), is implicit in the Italian position

f Specifically, the reform proposal allocates two new PNVM seats to the "industrialized states". According to Macqueen (2010), these two seats were intended for Germany and Japan. The reform proposal then allocates one PNVM seat to "developing states" in Africa, Asia and the GRULAC respectively. We allocate these seats to Nigeria, India and Brazil respectively

g The UfC reform proposal we examine here supersedes two earlier reform proposals made by the UfC (the "Blue" and "Green" Models). For a discussion of these reform proposals see Hoffmann and Ariyoruk (2005)

\section{Appendix 3: Simulation model}

\section{Election of UNSC members}

We begin by specifying, for each region, the number of seats of each membership category that are to be assigned in a given year. We are obliged to do this as only a subset of UNSC members complete their terms in a given year, so the timing of seats becoming vacant is not unique. For instance, in the present UNSC the GRULAC and the WEOG both receive two NPM seats: the GRULAC elects one of its seats each year-the sequence $\{1,1\}-$ whereas the WEOG elects both of its seats in odd years, and holds no elections in even years-the sequence $\{2,0\}$. As, the WEOG aside, the remaining regions display a preference for temporal smoothing of seat vacancies, we choose the timing of seat assignments to be that which is maximally smooth through time. Specifically, we look (under each structural reform) for the set of sequences that (i) makes maximally smooth the number of vacant seats per year within each region, and which (ii) also makes maximally smooth the total number of seats becoming vacant per year across regions. ${ }^{26}$

\footnotetext{
${ }^{26}$ Specifically, we employ a lexicographic procedure in which, first, we identify the sets of sequences that makes maximally smooth the number of vacant seats per year within each region. Second, among these sets of sequences, we identify those that maximally smooth the total number of vacant seats across regions. Last, if a unique set of sequences is not yet determined, a final choice is made according to a random draw from the remaining sequence sets.
} 
Under current UNSC rules, the UNGA simultaneously elects new NPMs to the UNSC in an annual ballot. In order to obtain a tractable electoral model for purposes of simulation, however, we suppose that elections are conducted sequentially, with countries elected oneby-one to each membership category in turn. As countries that win UNSC membership in the category elected first become ineligible for election to the membership category elected second, and so on, we assume that the elections for each membership category are held in order of desirability, with seats belonging to the most desirable membership category elected first. This assumption rules out the possibility that a country might not participate in the elections for the membership category contested first so as to ensure eligibility for a more desirable membership category to be contested later. Of the elected membership categories, PNVM membership is deemed the most desirable, with further membership categories ranked by term length (longer preferred to shorter), followed by renewable status (renewable preferred to non-renewable). The least desirable membership category2-year term, non-renewable-is therefore elected last. ${ }^{27}$

If, in year $t$, there are $n_{j k t}$ seats of membership category $k$ to be filled by new members from region $j$, then, in each of $n_{j k t}$ rounds, there is a new realization of a random variable that elects country $a_{i j}$ with probability $\rho_{i j k}$. A complication is that countries cannot have dual membership on the UNSC, so, if the same country is elected in more than one round, the process is repeated again in full until distinct countries are elected.

\section{UNSC expansion}

Under each structural reform, we denote the total number of UNSC seats (of all categories) belonging to region $j$ with a vector $\mathbf{n}^{0}=\left(n_{A f r i c a}^{0}, n_{A s i a}^{0}, \ldots, n_{W E O G}^{0}\right)$. We allow each new NPM seat to be allocated to region $j$ with probability $\psi_{j}$, subject to the condition that, when allocating $x$ new NPM seats, the realized allocation $\gamma_{j x}$ must satisfy $\gamma_{j x} \geq\left\lfloor\psi_{j} x\right\rfloor$ for all $j .{ }^{28}$ We divide the performed 100,000 realizations equally between each valid allocation.

How to choose the $\psi_{j}$ ? We note that one of our equity concepts-CE-is prescriptive regarding the assignment of UNSC seats to regions. Gould and Rablen (2016) prove (see their Proposition 4) that, under CE, the number of seats assigned to region $j, n_{j}$, satisfies ${ }^{29}$

$$
n_{j} \propto \sum_{a_{i j} \in R_{j}} \frac{\sqrt{q_{i j}}}{\beta_{i j}} \text { for all } j .
$$

We choose the $\psi_{j}$ separately for each structural reform. We do this as, to be scrupulously fair in evaluating each reform proposal, it is appropriate to give regions that benefit disproportionately from a given structural reform less weight in the subsequent expansion

\footnotetext{
27 The Rotate structural reform is the introduction of ten regional rotating seats to replace the ten existing NPM seats. To analyze this structural reform, we draw, for each region, the countries one-by-one without replacement under a uniform distribution to determine the order of rotation. In some instances, a country may be elected to a more desirable membership category when its "turn" for a rotating seat comes, in which case its turn as a rotating member is delayed until its UNSC term has ended. Similarly, a country may be ineligible to serve on the UNSC when its "turn" for a regional seat comes, in which case its turn is delayed until it becomes eligible.

${ }^{28}$ Hence, we do not consider extreme divisions of seats to regions in which the number of new NPM seats given to one or more region deviates significantly from its expected value $\psi_{j} x$.

29 Strictly, speaking, Gould and Rablen's (2016) Proposition 4 proves this result under "strong" CE, whereas here we employ what these authors term "weak" CE. It is straightforward to verify, however, that the proof of their Proposition 4 extends to the weak case.
} 
of the UNSC. Accordingly, for each structural reform, $s$, we compute the $\psi_{j}$ such that the UNSC attains the CE concept at the maximal expansion $x=193-15=178$. To do this, for each $s$, we (i) add 178 new NPM seats to $\mathbf{n}^{0}$ to give $\mathbf{n}^{178}$; (ii) compute the $\beta_{i j}$ for $\mathbf{n}^{178}$; (iii) use (A.1) to determine the $n_{j}$ that implement CE for $\mathbf{n}^{178}$; (iv) compute the vector of implied $x_{j}: \mathbf{x}=\mathbf{n}^{178}-\mathbf{n}^{0}$; and $(v)$ set $\psi_{j}=(1 / 178) x_{j}$. Although there is some modest variation across structural reforms, the typical values of the $\psi_{j}$ yielded by this procedure are: $\psi_{\text {Africa }}=0.29, \psi_{\text {Asia }}=0.36, \psi_{E E}=0.09, \psi_{\text {GRULAC }}=0.14$, and $\psi_{\text {WEOG }}=0.12$. Under these proportions the first ten additional NPM seats would be allocated three to Africa, four to Asia, and one to each of EE, the GRULAC and the WEOG.

\section{References}

Annan, K. A. (2005). In larger freedom: Towards development, security and human rights for all, A/59/2005. New York: United Nations.

AU. (2005). Reform of the Security Council, A/59/L.67. New York: United Nations.

Barnett, M. (2002). Eyewitness to a genocide: The United Nations and Rwanda. Ithaca: Cornell University Press.

Blum, Y. Z. (2005). Proposals for UN Security Council reform. American Journal of International Law, 99 (3), 632-649.

Bourantonis, D. (2005). History and politics of United Nations Security Council reform. Oxford: Routledge.

Coleman, J. S. (1971). Control of collectivities and the power of a collectivity to act. In B. Lieberman (Ed.), Social choice (pp. 269-300). New York: Gordon and Breach.

Cowling, K., Sacchetti, S., Sugden, R., \& Wilson, J. R. (2010). The United Nations and democratic globalization: a reconnaissance of the issues. In J. B. Davis (Ed.), Global social economy: development, work and policy (pp. 42-57). Abingdon: Routledge.

Cox, B. (2009). United Nations Security Council reform: Collected proposals and possible consequences. South Carolina Journal of International Law and Business, 6(1), 89-127.

Davis, R. (2010). An unrealistic proposal: An argument against the enlargement of the United Nations Security Council. International Affairs Review, 19(1), 19-38.

Dixon, W. J. (1983). The evaluation of weighted voting schemes for the United Nations General Assembly. International Studies Quarterly, 27(3), 295-314.

Dreher, A., Gould, M., Rablen, M. D., \& Vreeland, J. R. (2014). The determinants of election to the United Nations Security Council. Public Choice, 158(1-2), 51-83.

European Parliament (2011). The EU as a global actor: Its role in multilateral organisations, P7_TA(2011) 0229. Strasbourg: European Parliament

Fassbender, B. (2004). Pressure for Security Council reform. In D. M. Malone (Ed.), The UN Security Council: From the Cold War to the 21st century (pp. 341-356). Boulder: Lynne Rienner.

Felsenthal, D. S., \& Machover, M. (1997). Ternary voting games. International Journal of Game Theory, 26 (3), 335-351.

Felsenthal, D. S., \& Machover, M. (2001). The Treaty of Nice and qualified majority voting. Social Choice and Welfare, $18(3), 431-464$.

Felsenthal, D. S., \& Machover, M. (2003). The voting power approach: Response to a philosophical reproach. European Union Politics, 4(4), 473-479.

Felsenthal, D. S., \& Machover, M. (2004). Analysis of QM rules in the draft constitution for Europe proposed by the European Convention, 2003. Social Choice and Welfare, 23(1), 1-20.

Felsenthal, D. S., \& Machover, M. (2007). Analysis of QM rule adopted by the Council of the European Union. London: LSE Online.

Felsenthal, D. S., \& Machover, M. (2009). The QM rule in the Nice and Lisbon treaties: Future projections. Homo Oeconomicus, 26(3/4), 317-340.

Freixas, J. (2005). Banzhaf measures for games with several levels of approval in the input and output. Annals of Operations Research, 137(1), 45-66.

Freixas, J. (2012). Probabilistic power indices for voting rules with abstention. Mathematical Social Sciences, 64(1), 89-99.

Freixas, J., \& Zwicker, W. S. (2003). Weighted voting, abstention, and multiple levels of approval. Social Choice and Welfare, 21(3), 399-431. 
Frey, B. S., \& Stutzer, A. (2006). Strengthening the citizens' role in international organizations. Review of International Organizations, 1(1), 27-43.

G4. (2006). Security Council reform, A/60/L.46. New York: United Nations.

Gould, M., \& Rablen, M. D. (2016). Equitable representation in the councils of the United Nations: Theory and an application to the United Nations Security Council. Public Choice, 169(1-2), 19-51.

Hammer, C. (2002). Reforming the UN Security Council: Open letter to UN Secretary General Kofi Annan. Florida Journal of International Law, 15(2), 261-272.

Hartwig, R. (2008). Squaring the circle: A regional/economic proposal for reform of the United Nations Security Council. Critical Currents, 4, 41-75.

Hassler, S. (2013). Reforming the UN Security Council membership: The illusion of representativeness. Oxford: Routledge.

HLP. (2004). A more secure world: Our shared responsibility, A/59/565. New York: United Nations.

Hoffmann, W. (2006). Competing model: A Security Council with 20 members. New York: Center for UN Reform Education.

Hoffmann, W., \& Ariyoruk, A. (2005). Security Council reform models: Models A and B, Italian proposal, blue and green models and a new model $C$. New York: Center for UN Reform Education.

Hosli, M. O., Moody, O., O’Donovan, B., Kaniovski, S., \& Little, A. C. H. (2011). Squaring the circle? Collective and distributive effects of United Nations Security Council reform. Review of International Organizations, 6(2), 163-187.

Italy (2005). Statement by H. E. Marcello Spatafora Permanent Representative of Italy to the United Nations. Viewed at http://old.reformtheun.org/index.php? module=uploads \&func=download $\&$ fileId $=$ 238.

Kerby, W., \& Gøberler, F. (1996). The distribution of voting power in the UN: A power index analysis of some proposals for a reform of the UN Security Council. In L. A. Petrosjan \& V. V. Mazalov (Eds.), Game theory and applications II (pp. 133-141). New York: Nova Science Publishers.

Kirkup, J. (2009). Italy bidding for EU seat on UN Security Council, The Daily Telegraph, 14th November.

Köchler, H. (1995). The voting procedure in the United Nations Security Council. In H. Köchler (Ed.), Democracy and the international rule of law. Propositions for an alternative world order. Selected papers published on the occasion of the fiftieth anniversary of the United Nations (pp. 85-116). New York: Springer.

Leech, D. (2002a). Designing the voting system for the EU Council of Ministers. Public Choice, 113(3-4), 437-464.

Leech, D. (2002b). Voting power in the governance of the International Monetary Fund. Annals of Operations Research, 109(1-4), 375-397.

Leech, D. (2002c). The use of Coleman's power indices to inform the choice of voting rule with reference to the IMF governing body and the EU Council of Ministers. Warwick Economic Research Paper No. 645.

Leech, D., \& Leech, R. (2013). A new analysis of a priori voting power in the IMF: Recent quota reforms give little cause for celebration. In M. J. Holler \& N. Nurmi (Eds.), Power, voting, and voting power: 30 years after (pp. 389-410). Heidelberg: Springer.

Lindner, I. (2008). A special case of Penrose's limit theorem when abstention is allowed. Theory and Decision, 64(4), 495-518.

Loosemore, J., \& Hanby, V. J. (1971). The theoretical limits of maximum distortion: Some analytic expressions for electoral systems. British Journal of Political Science, 1(4), 467-477.

Macqueen, B. (2010). Muslim states and reform of the United Nations Security Council. Journal of Middle Eastern and Islamic Studies (in Asia), 4(3), 47-64.

Manno, C. S. (1966). Selective weighted voting in the UN General Assembly: Rationale and methods. International Organization, 20(1), 37-62.

Marchetti, R. (2008). Global democracy: For and against: Ethical theory, institutional design and social struggles. Abingdon: Routledge.

Martini, E. (2009). UN Security Council reform: Current developments. Working Paper No. 0926, Istituto Affari Internazionali.

Newcombe, H., Wert, J., \& Newcombe, A. (1971). Comparison of weighted voting formulas for the United Nations. World Politics, 23(3), 452-492.

O'Neill, B. (1996). Power and satisfaction in the United Nations Security Council. Journal of Conflict Resolution, 40(2), 219-237.

OEWG. (1994). Report on the progress of the work of the open-ended working group on the question of equitable representation on and increase in the membership of the Security Council, A/48/47. New York: United Nations. 
OEWG. (1997). Report of the open-ended working group on the question of equitable representation on and increase in the membership of the Security Council and other matters related to the Security Council, A/51/47. New York: United Nations.

OEWG. (2008). Report of the open-ended working group on the question of equitable representation on and increase in the membership of the Security Council and other matters related to the Security Council, A/62/47. New York: United Nations.

Panama (2007). Discurso del Embajador Ricardo Alberto Arias. Viewed at http://www.centerforunreform. org/system/files/panama_proposal.pdf.

Penrose, L. S. (1946). The elementary statistics of majority voting. Journal of the Royal Statistical Society, $109(1), 53-57$.

Rapkin, D. P., \& Strand, J. R. (2006). Reforming the IMF's weighted voting system. The World Economy, 29 (3), 305-324.

Russett, B., O’Neill, B., \& Sutterlin, J. (1996). Breaking the Security Council restructuring logjam. Global Governance, 2(1), 65-80.

Schwartzberg, J. E. (2003). Entitlement quotients as a vehicle for United Nations reform. Global Governance, $9(1), 81-114$.

Shapley, L. S., \& Shubik, M. (1954). A method for evaluating the distribution of power in a committee system. American Political Science Review, 48(3), 787-792.

Straffin, P. D. (1983). Power indices in politics. In S. J. Brams, W. F. Lucas, \& P. D. Straffin (Eds.), Political and related models (pp. 256-321). New York: Springer.

Straffin, P. D. (1993). Game theory and strategy. Washington, DC: The Mathematical Association of America.

Strand, J. R., \& Rapkin, D. P. (2011). Weighted voting in the United Nations Security Council: A simulation. Simulation \& Gaming, 42(6), 772-802.

Stutzer, A., \& Frey, B. S. (2006). Making international organizations more democratic. Review of Law and Economics, 1(3), 305-330.

UfC. (2005). Reform of the Security Council, A/59/L.68. New York: United Nations.

UfC (2010). Security Council reform, A/64.CRP.1. http://www.italyun.esteri.it/.

UN. (2012a). United Nations regional groups of member states. New York: United Nations.

UN. (2012b). United Nations financial situation continues to show encouraging signs of progress, says top management official, in detailed briefing to Budget Committee, GA/AB/4030. New York: United Nations.

UNGA. (1963). Question of equitable representation on the Security Council and the Economic and Social Council, A/RES/1991 (XVIII). New York: United Nations.

UNGA. (1992). Question of equitable representation on and increase in the membership of the Security Council, A/RES/47/62. New York: United Nations.

UNGA. (1993). Question of equitable representation on and increase in the membership of the Security Council, A/RES/48/26. New York: United Nations.

UNGA. (2011). Participation of the European Union in the work of the United Nations, A/65/L.64/Rev.1. New York: United Nations.

Volacu, A. (2015). A priori voting power distribution under contemporary Security Council reform proposals. Journal of International Relations and Development. doi:10.1057/jird.2015.32.

von Freiesleben, J. (2008). Security Council reform. In E. Perry (Ed.), Managing change at the United Nations (pp. 1-20). New York: Center for UN Reform Education.

Weiss, T. G. (2005). Overcoming the Security Council reform impasse. Dialogue on Globalization Occasional Paper No. 14

Weiss, T. G., \& Young, K. E. (2005). Compromise and credibility: Security Council reform? Security Dialogue, 36(2), 131-154.

Wouters, J., \& Ruys, T. (2005). Security Council reform: A new veto for a new century?. Brussels: Royal Institute for International Relations.

Zifcak, S. M. (2006). United Nations reform: Heading north or south? Global Change, Peace \& Security, 18 (3), 135-152. 